\title{
Multimodal Treatment of Locally Advanced Gastric Cancer: Will the West Meet the East?
}

\author{
Luigina Graziosi, MD, PhD, Elisabetta Marino, MD, and Annibale Donini, MD
}

General and Emergency Surgery, University of Perugia, Perugia, Italy

Dear editor,

We read with particular interest the paper by Nakamura et al. ${ }^{1}$ published in Annals of Surgical Oncology in November 2018.

We are greatly surprised by the excellent survival outcomes shown in both trials. As a matter of fact, pStage 3 patients exhibited a 3-year overall survival (OS) of about $75 \%$ to $80 \%$. These patients are really incredible compared with Western patients.

In our Italian surgical center, pStage 3 relapse-free survival (RFS) and OS results are worse. In the last survival analysis, pStage $3 \mathrm{C}$ patients showed a survival comparable with stage 4 survival according to the newest 8th tumor-node-metastasis (TNM) staging system. Our results are similar to those of other centers in Western and Eastern countries. $^{2}$

Also, $\operatorname{In}^{3}$ in his recent work described a poor 3-year OS ranging from 40 to $13 \%$ for pStage 3 patients after curative surgery. In addition, we well know that adjuvant chemotherapy does not add such a large survival benefit, highlighting the important and predominant role of surgery with an adequate lymphadenectomy in the treatment of locally advanced gastric cancer. ${ }^{4}$

We are convinced that gastric cancer in the East differs biologically from gastric cancer in the West, but we cannot explain how pStage 3 disease has such a long 3-year RFS and a percentage so different from ours. This cannot be explained only by the use of S1, a drug not available in Italy to date.

(C) Society of Surgical Oncology 2019

First Received: 30 November 2018;

Published Online: 3 January 2019

E. Marino, MD

e-mail: elisabetta.marino1986@gmail.com
It could be useful to separate pStage 3 into stages $3 a, 3 b$, and $3 \mathrm{c}$ according to the 8th TNM staging system to discriminate the real subgroup of patients that could benefit from adjuvant chemotherapy after gastric resection. Probably, this would not have been possible with the small studied population.

We will use a longer follow-up period to observe possible survival outcomes or to confirm them. In the future, molecular investigations must be conducted for a better understanding of the biologic differences and behaviors between East and West.

\section{REFERENCES}

1. Nakamura Y, Yamanaka T, Chin K, Cho H, Katai H, Terashima M, et al. Survival outcomes of two phase 2 studies of adjuvant chemotherapy with S-1 plus oxaliplatin or capecitabine plus oxaliplatin for patients with gastric cancer after D2 gastrectomy. Ann Surg Oncol. https://doi.org/10.1245/s10434-018-7063-8.

2. Qiu MZ, Wang ZX, Zhou YX, Yang DJ, Wang FH, Xu RH. Proposal for a new TNM stage based on the 7th and 8th American Joint Committee on Cancer pTNM staging classification for gastric cancer. J Cancer. 2018;9:3570-6.

3. In H, Solsky I, Palis B, Langdon-Embry M, Ajani J, Sano T. Validation of the 8th edition of the AJCC TNM staging system for gastric cancer using the National Cancer Database. Ann Surg Oncol. 2017;24:3683-91.

4. Greenleaf EK, Kulaylat AN, Hollenbeak CS, Almhanna K, Wong J. Timing of adjuvant chemotherapy and impact on survival for resected gastric cancer. Ann Surg Oncol. 2016;23:4203-13.

Publisher's Note Springer Nature remains neutral with regard to jurisdictional claims in published maps and institutional affiliations. 